\title{
Expression of OmpC and OmpF porin proteins and survival of Escherichia coli under photooxidative stress in Black Sea water
}

\author{
Cihan Darcan* \\ Department of Molecular Biology and Genetics, Faculty of Arts and Sciences, Bilecik Şeyh Edebali University, \\ 11000-Bilecik, Turkey
}

\begin{abstract}
In the present study, the synthesis of OmpC and OmpF porins (outer membrane proteins $\mathrm{C}$ and F, respectively) of Escherichia coli under photooxidative stress in Black Sea water and the roles of RpoS (the starvation/stationary phase sigma factor, $\sigma^{38}$ ) and EnvZ (a transmembrane environmental sensor protein) in changing porin protein expression were investigated. The $t_{99}$ (time required for a 2 log reduction) values for wild-type E. coli W3110 and MSZ31 (envZ $Z^{-}$) under photooxidative stress were observed to be 14.3 and $16.8 \mathrm{~h}$, respectively, while for porin-deficient mutants MKC505 $\left(o m p C^{-}\right), \operatorname{MH} 621\left(o m p F^{-}\right), \operatorname{MKCF} 36\left(o m p F^{-} o m p C^{-}\right)$, and MSR31 (ompR $\left.{ }^{-}\right)$they were 10.6, 10.2, 9.8 and $9.1 \mathrm{~h}$, respectively. Further, when the porins or $\operatorname{omp} R$ were deleted, the resistance to photooxidative stress decreased. OmpC and OmpF porin expression increased in all studied transcriptional fusion strains (wild type and mutants) in control microcosms, and almost completely decreased under photooxidative stress in the test microcosms, which consisted of light exposure with methylene blue added as a photosensitizer. Thus, it could be concluded that RpoS and EnvZ regulation of the synthesis of OmpC and $\mathrm{OmpF}$ is not photooxidation-dependent. This study determined for the first time that the expression of $o m p C$ in brackish water is influenced by RpoS.
\end{abstract}

KEY WORDS: Porin $\cdot$ Photooxidation $\cdot$ Escherichia coli $\cdot$ Black Sea $\cdot$ RpoS $\cdot$ EnvZ

\section{INTRODUCTION}

In the aquatic environment, various factors are known to affect the surival of enteric bacteria, including temperature (Arana et al. 2010), starvation stress (Muela et al. 2008), osmolarity (Munro et al. 1989), pH (Darcan et al. 2009a), predation by protozoa (Thelaus et al. 2009), and exposure to visible and UV light (İdil et al. 2010, 2011). In this context, oxidative stress may be one of the most serious factors influencing the survival of bacteria, causing damage to cells because of reactive oxygen radicals. Reactive oxygen species (ROS) are produced by light under natural conditions. Light may have either a direct effect or an indirect effect on cells via photosensitizer molecules and generate reactive oxygen radicals (Özkanca et al. 2002, Ziegelhoffer \& Donohue 2009). The ROS that cause oxidative stress can be classified as superoxide anion $\left(\mathrm{O}_{2}{ }^{-}\right)$, hydrogen peroxide $\left(\mathrm{H}_{2} \mathrm{O}_{2}\right)$, singlet oxygen $\left({ }^{1} \mathrm{O}_{2}\right)$, and hydroxyl (HO) radicals (Storz \& Imlay 1999). ROS may also be generated by a number of other biologically relevant processes that do not involve light, e.g. they may be generated by neutrophils to resist bacterial infections.

ROS can cause serious damage to cells in aquatic environments. Bacteria use various protection mechanisms to avoid damage. These mechanisms are either enzymatic or non-enzymatic (Storz \& Imlay 1999). The majority of them are controlled by OxyR and SoxRS regulons (Zheng et al. 1999). The protection mechanisms include factors that have direct effects, such as catalase, superoxide dismutase, glutathione peroxidase, glutathione, alpha tochoperol (Storz \& Imlay 1999, Zheng et al. 1999), or indirect ones, such as 
changes in outer membrane permeability (Özkanca et al. 2002). Gram-negative bacteria adapt their outer membrane permeability by modulating the expression of porins. Porin proteins in the outer membrane of Escherichia coli can occur as both specific and nonspecific pore-forming proteins. The $\mathrm{OmpC}$ and $\mathrm{OmpF}$ porin proteins play an important role in the relationship of the cell with the outer environment and are known to control the permeability of $<600 \mathrm{kDa}$ hydrophilic polar solutes across the outer membrane of Gram-negative bacteria (Achouak et al. 2001).

The expression levels of Escherichia coli OmpC and $\mathrm{OmpF}$ are controlled by the $о \mathrm{mp} B$ regulon, which is comprised of envZ and ompR genes that form the two-component regulatory system (Hall \& Silhavy 1981). The expression of ompC and $o m p F$ is upregulated by osmolarity, $\mathrm{pH}$, ionic strength, and temperature (Özkanca \& Flint 2002, Darcan et al. 2009b). Additional regulation can also occur through responses elicited by antibiotics, heavy metals, detergents, bile salts, or aromatic compounds, which may decrease the amount of porins in the outer membrane (Pratt et al. 1996, Pagès et al. 2008, Chubiz \& Rao 2011). The regulation of porin proteins involves transcriptional and posttranscriptional factors, many of which are only expressed under specific conditions. In addition to EnvZ and OmpR, several other regulators are involved, such as PhoB, Lrp, Rob (Ferrario et al. 1995, Goosen \& Van de Putte 1995, Atlung \& Ingmer 1997, Painbeni et al. 1997, Deighan et al. 2000, Chubiz \& Rao 2011). Porins are also regulated posttranscriptionally by sRNAs, such as MicF and MicC (Delihas \& Forst 2001, Nikaido 2003, De la Cruz \& Calva 2010). Porin proteins are controlled by other twocomponent phosphorelay systems such as CpxR and ArcA (Matsubara et al. 2000, Batchelor et al. 2005). These factors reveal a very complex synthesis mechanism of OmpC and OmpF, necessary for the survival of $E$. coli under various stress conditions.

The importance of porins for survival under photooxidative stress in aquatic environments as well as the molecular mechanisms driving their regulation and synthesis are not well understood. Therefore, the aim of the present study was to investigate the level of expression and the role of porin proteins in Escherichia coli for survival under photooxidative stress in Black Sea water, as well as to determine the role of EnvZ and RpoS.

\section{MATERIALS AND METHODS}

\section{Bacterial strains}

The Escherichia coli strains used in this study are listed in Table 1. Porin-deficient mutants of bacteria were used for survival experiments. In these strains, the porin genes have been knocked out with antibiotic-resistance genes in order to understand the role of porins (Ferrario et al. 1995, Sato et al. 2000). Additionally, transcriptional fusion mutants containing the functional lacZ gene (Liu \& Ferenci 2001) were used in order to determine porin expression change under photooxidative stress in Black Sea water (Table 1).

\section{Survival and $\beta$-galactosidase activity assays of Escherichia coli in Black Sea water}

Water samples for each experiment were collected from the Black Sea coast near Samsun, Turkey. Brackish water microcosms were prepared by filtering water samples through Whatman No.1 filter paper and then autoclaved at $121^{\circ} \mathrm{C}$ in flasks covered with aluminum foil. All Escherichia coli strains were incubated in nutrient broth overnight at $37^{\circ} \mathrm{C}$. The culture $(10 \mathrm{ml})$ was harvested by centrifugation at $8000 \times g$ for $5 \mathrm{~min}$. The cells were washed twice with autoclaved brackish sea water $(1 \mathrm{ml})$, and then the pellet was resuspended in autoclaved brackish water $(5 \mathrm{ml})$. The resuspended culture was inoculated into the filtered, autoclaved water microcosm. Beakers

Table 1. Escherichia coli strains used in this study

\begin{tabular}{|lll|}
\hline \multirow{2}{*}{ Bacterial strain } & \multicolumn{1}{c|}{ Genotype } & Source \\
\hline E. coli W3110 & Wild type & Sato et al. 2000 \\
MSR31 & W3110 ompR::Tn10 & Sato et al. 2000 \\
MSZ31 & W3110 envZ::Kan & Sato et al. 2000 \\
MKCF36 & MH20 (ompF-lacZ) 16-21 & Sato et al. 2000 \\
& (Hyb) ompF ompC::Kan & \\
MH621 & MH20 (ompF-lacZ) 16-21 & Ferrario et al. 1995 \\
& (Hyb) ompF ompC & \\
MKC505 & MH20 (ompF-lacZ) 16-21 & Sato et al. 2000 \\
& (Hyb) ompF ompC::Kan & \\
MH225 & MC4100 U(ompC-lacZ+)10-25 & Liu \& Ferenci 2001 \\
& (wild type) & \\
MH513 & MC4100 araD+U(ompF'-lacZ+) & Liu \& Ferenci 2001 \\
& 16-13 (wild type) & \\
BW3343 & MH513 envZ60::Tn10 & Liu \& Ferenci 2001 \\
BW3345 & MH225 envZ60::Tn10 & Liu \& Ferenci 2001 \\
BW3301 & MH513 rpoS::Tn10 & Liu \& Ferenci 2001 \\
BW3302 & MH225 rpoS::Tn10 & Liu \& Ferenci 2001 \\
&
\end{tabular}


containing filtered, autoclaved water $(100 \mathrm{ml})$ with a final bacterial cell concentration of $5 \times 10^{6} \mathrm{cfu} \mathrm{ml}^{-1}$ for survival tests, and $5 \times 10^{8} \mathrm{cfu} \mathrm{m}^{-1}$ for measuring $\beta$ galactosidase activity were used. The tops of the beakers were wrapped with clingfilm to prevent contamination of the microcosm.

Methylene blue (MB) dye (Merck; final concentration $1.5 \mu \mathrm{M}$ ) was added as a photosensitizer to all test microcosms exposed to light (L+MB) and to the positive control that was incubated in the dark (D+MB). As positive controls, a series of samples without the photosensitizer were also incubated in the dark (D) and light (L). All microcosms were incubated at $24^{\circ} \mathrm{C}$. $\mathrm{L}+\mathrm{MB}$ and $\mathrm{L}$ microcosms were then exposed to 6 visible light sources (white wavelength 400 to $700 \mathrm{~nm}$ ). The light intensity was measured in the beakers using a radiometer and determined to be $4800 \pm$ $76 \mathrm{~lx}$, mean $\pm \mathrm{SD}$.

Survival tests were performed using the surface spread plate technique, and total bacteria counts were performed by acridine orange direct count for transcriptional fusion mutants (Hobbie et al. 1977). Bacterial samples $(5 \mathrm{ml})$ for total bacterial counts were filtered through black nuclepore track-etched membrane (Whatman) and treated with acridine orange dye $(0.01 \%$ final concentration). Filters were then dried and examined using a UV microscope (Nikon Eclipse E600). $\beta$-galactosidase ( $\beta$-gal) activity was measured using the method of Miller (1992). Brackish water microcosm samples $(250 \mu \mathrm{l})$ were taken at $2 \mathrm{hr}$ intervals and mixed with $750 \mu \mathrm{l} \mathrm{Z-buffer}$ (Miller 1992) and 2 to 3 drops of toluene. These tubes were then incubated on a shaker for $45 \mathrm{~min}$ at $37^{\circ} \mathrm{C}$ and $160 \mathrm{rpm}$, kept at $28^{\circ} \mathrm{C}$ for $5 \mathrm{~min}$ in a water bath, combined with $200 \mu \mathrm{l}$ ONPG (stock $4 \mathrm{mg} \mathrm{ml}^{-1}$ ONPG), and incubated for $1 \mathrm{~h}$. Then, $1 \mathrm{M} \mathrm{Na}_{2} \mathrm{CO}_{3}$ $(500 \mu \mathrm{l})$ was added. Samples were measured spectrophotometrically at 420 and $550 \mathrm{~nm}$ wavelengths and the results converted to the standardized amount of $\beta$-gal activity, measured in Miller Units (MU), according to the formula given in Miller (1992).

\section{Data analysis and statistics}

All count data were expressed as mean $( \pm \mathrm{SD})$ values of log counts from 3 replicated experiments. The survival time was expressed as $t_{99}$ values (the time for a 2 log decrease in the culturable count from the initial inoculum size). Differences between treatments and the time-dependent change were analyzed using the Student's $t$-test (results considered significant at $\mathrm{p}<0.05$ ).

\section{RESULTS}

\section{Survival of wild-type Escherichia coli and its porin mutants}

The present study was performed to investigate how different porin proteins influenced the survival of E. coli in Black Sea water under photooxidative stress. The numbers of wild-type and mutant E. coli cells gradually decreased during a $10 \mathrm{~h}$ incubation period when exposed to the test treatment $(\mathrm{L}+\mathrm{MB}$; Table 2). Survival experiments showed that the culturable count of E. coli strains declined faster in the $\mathrm{L}+\mathrm{MB}$ treatment than in the other treatments (Table 2). No significant decrease was observed in the dark or light control samples for the period of experimentation ( $\mathrm{L}, \mathrm{D}, \mathrm{D}+\mathrm{MB}$; Table 2 ). The envZ mutant displayed a longer survival time compared to the wild type in the L+MB treatment $(\mathrm{p}<0.05$; Table 3$)$. Further, the ompCompF and ompR mutants displayed shorter survival times when compared to wild-type $E$. coli and ompC and ompF mutants ( $\mathrm{p}<0.05$; Table 3$)$.

\section{Effect of photooxidative stress on porin protein synthesis}

A change was observed in the synthesis level of OmpF and OmpC of Escherichia coli under photooxidative stress in brackish water. As shown in Fig. 1, both OmpF and OmpC synthesis decreased after exposure to photooxidative stress. While porin protein synthesis increased in control samples ( $, \mathrm{D}+\mathrm{MB}, \mathrm{L})$, the expression in $\mathrm{L}+\mathrm{MB}$ samples decreased very quickly. This reduction was not a result of bacteria death as the numbers of all bacteria in the enzyme experiments did not decline by more than 1 log (total bacteria with acridine orange were also counted; total bacteria counts and culturable counts in all bacteria were approximately the same, data not shown). The expression of ompC genes $(192 \pm 11 \mathrm{MU})$ of $E$. coli, which were transferred after $18 \mathrm{~h}$ incubations in nutrient broth, was greater than those of ompF $(110 \pm$ $13 \mathrm{MU}$ ) during the stationary phase. While OmpF synthesis decreased from $110 \pm 13$ to $42 \pm 5 \mathrm{MU}$ after $8 \mathrm{~h}$ under photooxidative stress in brackish water $\mathrm{p}<$ 0.05), OmpC synthesis decreased from $192 \pm 11$ to $57 \pm 10 \mathrm{MU}(\mathrm{p}<0.05)$. On the other hand, OmpC synthesis increased by approx. 1.5 times in all control samples $\left(\mathrm{L}, \mathrm{D}, \mathrm{D}+\mathrm{MB}_{i} \mathrm{p}<0.05\right)$, and $\mathrm{OmpF}$ synthesis also increased approx. 2.7 times in the light control samples (L) and 3 times for all dark samples in brackish water $(\mathrm{D}, \mathrm{D}+\mathrm{MB} ; \mathrm{p}<0.05)$. 
Table 3. Escherichia coli. Survival times expressed as $t_{99}$ values (the time for a 2-log decrease in the culturable count from the initial inoculum size) of wild-type and mutant strains under photooxidative stress in sea water. Only data from the test microcosm (light-exposed with methylene blue photosensitizer, L+MB) are shown

\begin{tabular}{|lc|}
\hline Bacteria & $t_{99}(\mathrm{~h})$ \\
\hline E. coli W3110 (wild type) & 14.3 \\
MSZ31 (envZ $Z^{-}$ & 16.8 \\
MSR31 (ompR $\left.)^{-}\right)$ & 9.1 \\
MKC505 $\left(o m p C^{-}\right)$ & 10.6 \\
MH621 (ompF $\left.F^{-}\right)$ & 10.2 \\
MKCF36 (omp $C^{-}$ompF $\left.^{-}\right)$ & 9.8 \\
\hline
\end{tabular}

\section{Effect of RpoS and EnvZ on ompC and ompF expression under photooxidative stress}

EnvZ is an osmosensor of a two-component phosphorelay system and is responsible for the phosphorylation and dephosphorylation of OmpR. The synthesis of OmpC and OmpF in envZ-mutant Escherichia coli under photooxidative stress decreased, similar to that of the wild type. While ompC expression of envZ-mutant $E$. coli under photooxidative stress decreased from $55 \pm 3$ to $6 \pm 1 \mathrm{MU}$, it also decreased to $44 \pm 3 \mathrm{MU}, 34.8 \pm 4.6 \mathrm{MU}$, and $40 \pm$ $7 \mathrm{MU}$ in the $\mathrm{D}, \mathrm{L}$ and $\mathrm{D}+\mathrm{MB}$ control microcosms, respectively ( $p<0.05 ;$ Fig. 2$)$. In contrast, while the synthesis of $\mathrm{OmpF}$ also decreased from $57 \pm 8$ to $7 \pm$ $2 \mathrm{MU}$ in the $\mathrm{L}+\mathrm{MB}$ microcosm, this porin increased in all 3 control microcosms, to $76 \pm 5 \mathrm{MU}, 105 \pm 13 \mathrm{MU}$ and $94 \pm 11 \mathrm{MU}$ in the $\mathrm{L}, \mathrm{D}$ and $\mathrm{D}+\mathrm{MB}$ microcosms, respectively ( $p<0.05$; Fig. 2$)$. The envZ-deficient $E$. coli could not synthesize the OmpC porin protein in the control microcosms like the wild type; however, there was a remarkable proportion of envZ-independent OmpF synthesis in Black Sea water.

The synthesis of OmpF and OmpC in rpoS-mutant Escherichia coli was found to decrease remarkably under photooxidative stress in the water microcosm, similar to the wild type. While OmpF synthesis in rpoS-mutant $E$. coli decreased from $578 \pm 57$ to $63 \pm$ $17 \mathrm{MU}, \mathrm{OmpC}$ synthesis decreased from $185 \pm 10$ to $32 \pm 13 \mathrm{MU}$ under photooxidative stress in brackish water (Figs. $3 \& 4$ ). On the other hand, OmpF synthesis in the control microcosms increased from $586 \pm 83$ to $927 \pm 99 \mathrm{MU}$ in the light control, $983 \pm$ $54 \mathrm{MU}$ in the $\mathrm{D}+\mathrm{MB}$ control, and $863 \pm 39 \mathrm{MU}$ in the dark control (Fig. 3A). The expression of ompC in rpoS-deficient $E$. coli was found to be the same as the wild type at $0 \mathrm{~h}(190 \pm 23 \mathrm{MU}$ for wild type, Fig. 4B; $186 \pm 11 \mathrm{MU}$ for the rpoS mutant, Fig. 3B), but the 
expression of ompC in wild-type and rpoS-mutant $E$. coli was approximately $320 \pm 20$ (Fig. 1B) and $248 \pm$ $20 \mathrm{MU}$ (Fig. 3B), respectively, after $8 \mathrm{~h}$ of incubation in all control Black Sea water microcosms ( $p<0.05)$.

\section{DISCUSSION AND CONCLUSIONS}

Aquatic environments contain very variable stress factors, such as sunlight, that affect the survival of bacteria. Bacteria must use regulatory mechanisms for survival when exposed to stress conditions in environments such as brackish water. One such

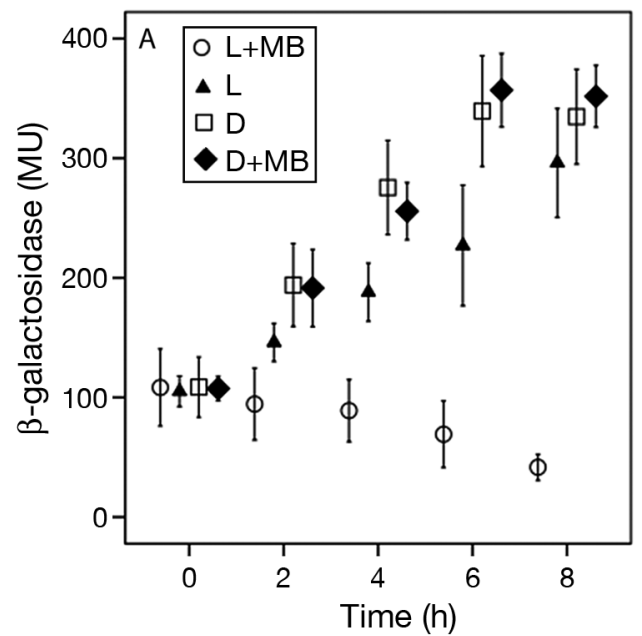

mechanism in Gram-negative bacteria is the regulation of outer membrane permeability provided by porins (Gauthier et al. 1992).

In the present study, the survival time of Escherichia coli was found to decrease under photooxidative stress when compared with control microcosms. There are several existing studies on the effects of photooxidative stress on the survival of bacteria (Muela et al. 2002, Sinton et al. 2007, Ziegelhoffer \& Donohue 2009, Darcan \& Aydin 2012). Highly reactive oxygen species attack cell compartments, resulting in cell death or viable but nonculturable cell forms (İdil et al. 2011).

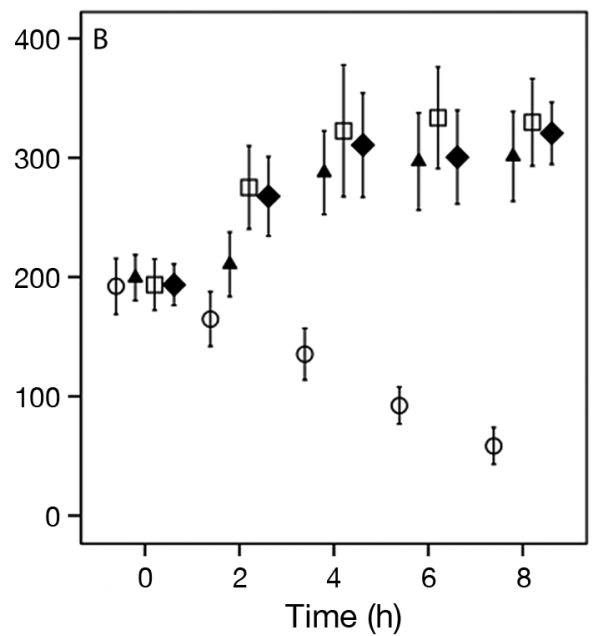

Fig. 1. Escherichia coli. Synthesis of 2 porin proteins, (A) OmpF (MH513) and (B) OmpC (MH225), by wild-type E. coli (strain in parentheses) under photooxidative stress as measured by mean $( \pm \mathrm{SD}) \beta$-galactosidase activity from 3 replicated independent experiments. Methylene blue (MB) was added as a photosensitizer to the light-exposed test microcosm (L+MB) and the dark control microcosm (D+MB). Light control (L) and dark control (D) microcosms without photosensitizer were also used. MU: Miller Units
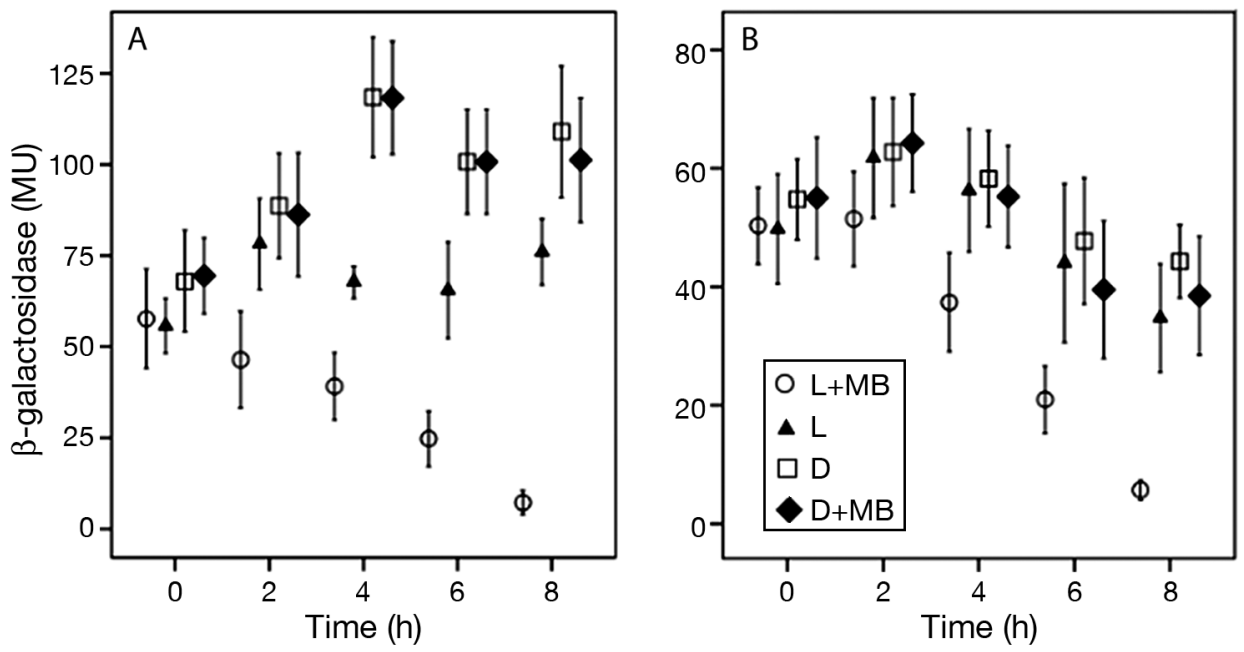

Fig. 2. Escherichia coli. Synthesis of 2 porin proteins, (A) OmpF (BW3343) and (B) OmpC (BW3345), by envZ-mutant E. coli (strain in parentheses) under photooxidative stress as measured by mean $( \pm$ SD) $\beta$-galactosidase activity from 3 replicated independent experiments. See Fig. 1 for treatment descriptions and abbreviations 

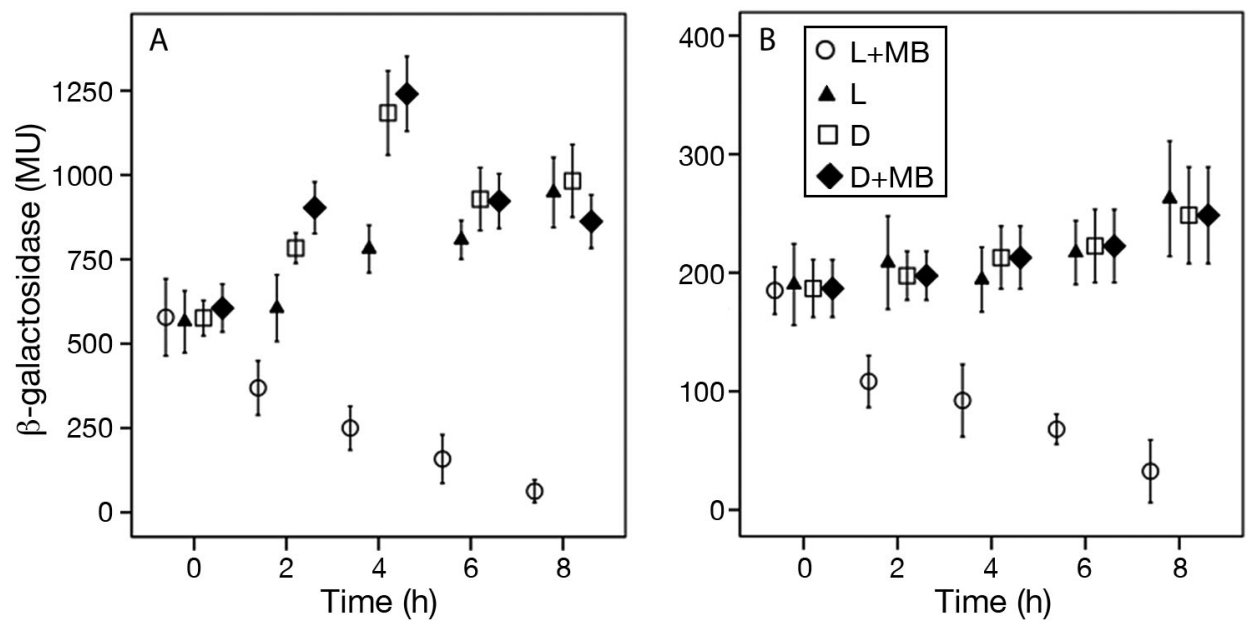

Fig. 3. Escherichia coli. Synthesis of 2 porin proteins, (A) OmpF (BW3301) and (B) OmpC (BW3302), by rpoS-mutant E. coli (strain in parentheses) under photooxidative stress as measured by mean ( \pm SD) $\beta$-galactosidase activity from 3 replicated independent experiments. See Fig. 1 for treatment descriptions
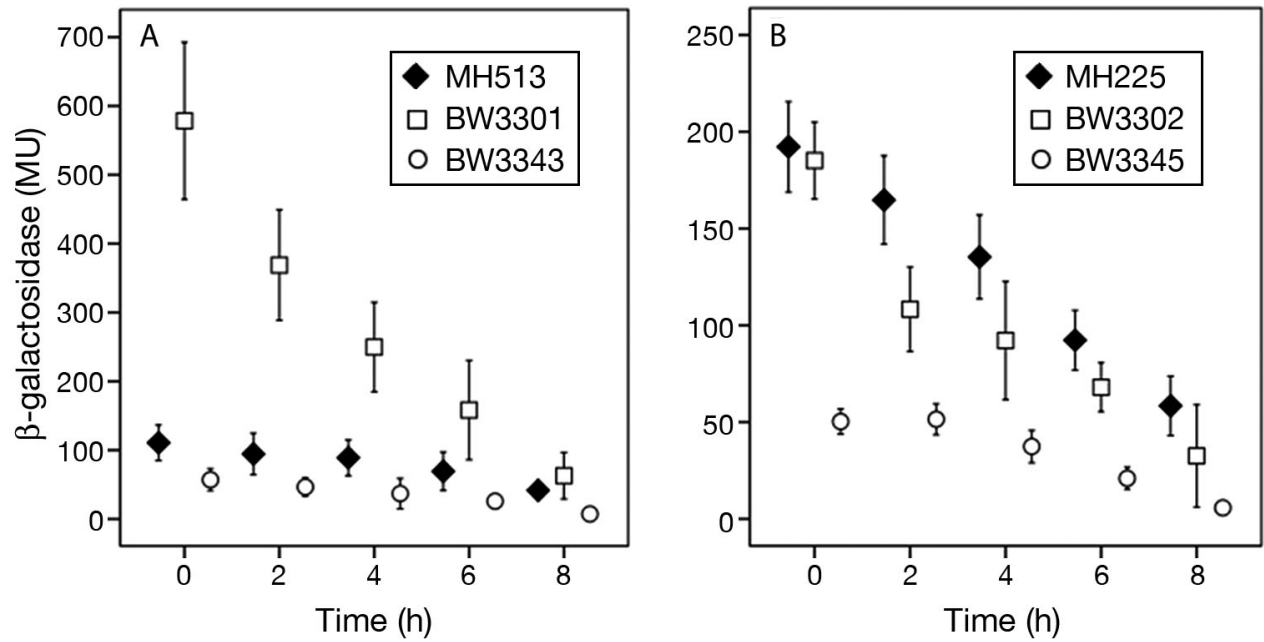

Fig. 4. Escherichia coli. Synthesis of 2 porin proteins, (A) OmpF and (B) OmpC, by 6 different strains of E. coli, including 2 wildtype (MH513 and MH225) and 4 mutant (envZ-mutant BW3343 and BW3345 and rpoS-deficient BW3301 and BW3302) strains under photooxidative stress as measured by mean $( \pm \mathrm{SD}) \beta$-galactosidase activity from 3 replicated independent experiments. Only data from the test microcosm (light-exposed with methylene blue photosensitizer, L+MB) are shown

A few studies determined that the deletion of 6 different genes had a great effect on the survival of $E$. coli in sea water or brackish water; 2 of these genes are ompC and $o m p F$ porin genes (Rozen \& Belkin 2001, Darcan et al. 2003). In the present study, porin proteins (OmpC and $\mathrm{OmpF}$ ) were shown to be important in providing $E$. coli with resistance against photooxidative stress in Black Sea water. The culturability of $E$. coli was more affected by ompC-ompF and ompR mutations compared to the other mutations and the wild type. Another study indicated that the decrease in synthesis of OmpA porin under photooxidation was caused by visible irradiation (Muela et al. 2008).
A study of oxidative stress indicated that the elimination of $o m p F$ did not increase the resistance of $E$. coli to the superoxide-generating agent menadione (Greenberg 1989). Porins might affect several biological functions, thus allowing a rapid adaptation and survival of bacterial cells. However, the physiological importance and requirement of $\mathrm{OmpC}$ and OmpF for the survival of $E$. coli under photooxidative stress remains unclear. In the present study, the envZ-deficient $E$. coli had longer survival times than wild-type $E$. coli under photooxidative stress in brackish water, which agrees with other studies on survival of envZ-mutated E. coli under stress conditions (Darcan et al. 2003, 2009a). 
Gram-positive bacteria are sensitive to photosensitization by various dyes, while Gram-negative bacteria are more resistant. This difference can be explained by the structural differences in the cell walls and outer membrane (Dahl et al. 1989). The control of the outer membrane plays a role in Gram-negative bacteria protection against stress conditions. In the present study, expression of ompC and ompF in Escherichia coli was reduced under photooxidative stress in Black Sea water. However, the porin expression of $E$. coli increased in the control microcosms. The expression of ompC and ompF decreased because of photooxidative stress despite the high osmolarity and alkaline $\mathrm{pH}(\mathrm{pH}$ 8.2) in brackish water. Özkanca et al. (2002) determined that the synthesis of both OmpC and OmpF in Salmonella typhimurium was decreased by $50 \%$ after $5 \mathrm{~h}$ incubation under photooxidative stress in seawater.

Nevertheless, the molecular mechanisms of expression of porin proteins under the effect of photooxidative stress in natural aquatic environments remain unclear. Chou et al. (1993) showed that micF transcription was strongly inducible but wholly dependent on the soxRS locus in response to treatment with the superoxide-generating agent paraquat. The OmpF porin level decreased as this transcript prevented ompF mRNA translation, whereas OmpC expression had no effect (Chou et al. 1993). In the present study, the expression of ompF and ompC was observed to decrease because of the effect of photooxidative stress in Black Sea water.

Porin proteins are regulated by the EnvZ-OmpR 2phosphorelay system (Forst et al. 1989). If ompR, which is a master regulator, is deleted, porin proteins cannot be synthesized (Forst et al. 1989, Darcan et al. 2009b). However, if envZ, which is an osmosensor, is deleted, both OmpC and OmpF can be synthesized (Liu \& Ferenci 2001, Darcan et al. 2009b). The present study showed that EnvZ had no role in photooxidation-dependent porin expression. However, $E n v Z$ was required for the expression of $o m p C$, which has a very important role in $E$. coli survival. While the expression of ompC in wild-type $E$. coli increased in control microcosms, the expression of ompC in envZdeficient $E$. coli decreased. The expression of ompC is dependent on osmolarity in brackish water. EnvZ is an osmosensor (Slauch et al. 1988), and therefore, the expression of ompC was regulated by EnvZ. The expression of $o m p F$ is expected to decrease in brackish water (Lan \& Igo 1998) but the expression of ompF was found to increase in brackish water in the present study, which is probably related to the alkaline $\mathrm{pH}$ (8.2) and osmolarity in Black Sea water. Darcan et al. $(2005,2009 b)$ determined that the expression of $o m p F$ and $o m p C$ was approximately the same amount in alkaline $\mathrm{pH}$ (8.3) and high osmolarity in minimal medium or brackish water. As a result, the expression of ompC was EnvZ-dependent, and the expression of $o m p F$ played a role in a lot of factors such as H-NS, IHF (Fig. 5) other than EnvZ in Black Sea water.

The RpoS plays a very important role in the survival of Escherichia coli under stress conditions (Liu \& Ferenci 2001, Rozen \& Belkin 2001). The expression of $o m p F$ is controlled via MicF RNA, which is negatively affected by RpoS, and the expression of ompF is decreased by RpoS (Pratt et al. 1996, Liu \& Ferenci 2001). In contrast, the relationship between RpoS and $o m p C$ is not mechanistic (Liu \& Ferenci 2001). The present study found that the expression of ompC was not regulated by RpoS under photooxidative stress in Black Sea water. However, although a previous study showed that the expression of ompC was not con-

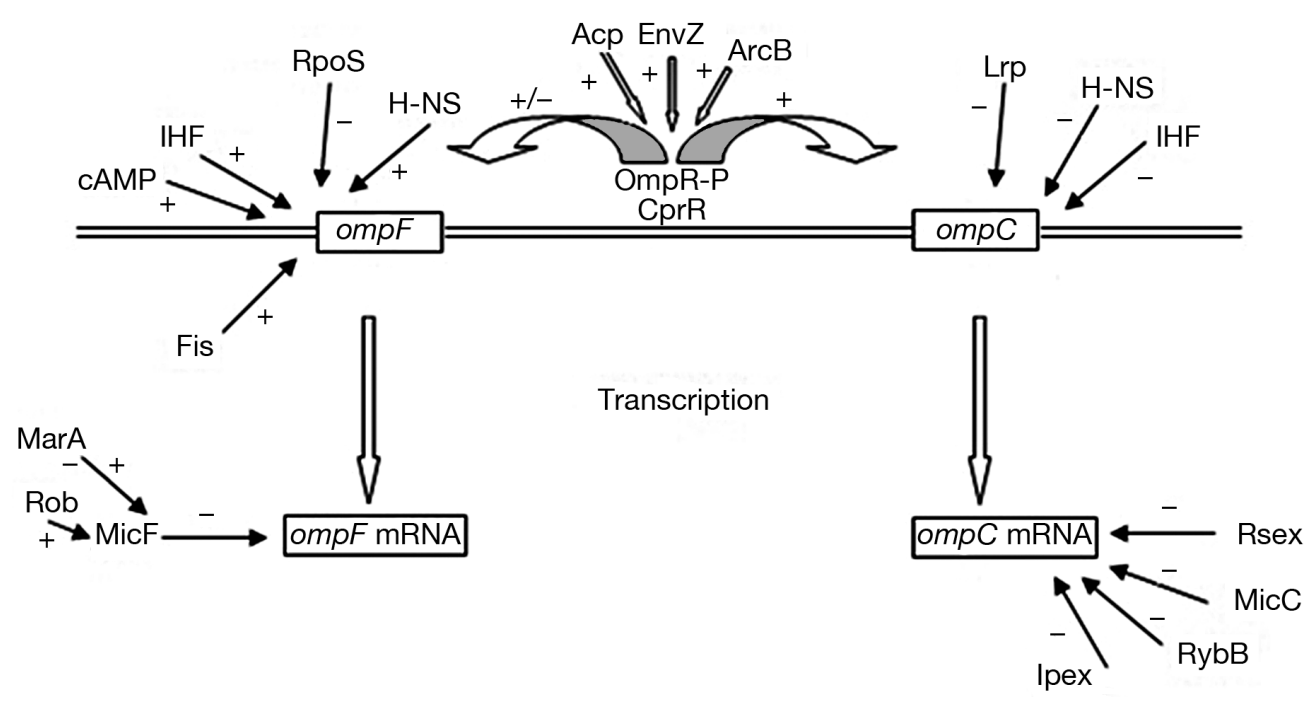

Fig. 5. Escherichia coli. Transcriptional and posttranscriptionl regulation of porin expression in E. coli. +: up regulation, -:down regulation 
trolled by RpoS (Liu \& Ferenci 2001), in the present study a knock-out in rpoS influenced ompC expression in the control microcosms. According to my results, RpoS has an unknown role in the expression of $o m p C$ in brackish water; however, rpoS has an indirect effect on the expression of ompC. The expression of ompF in rpoS-deficient $E$. coli was higher than that of wild-type $E$. coli under different conditions in several studies (Liu \& Ferenci 2001, Darcan 2005, Darcan et al. 2009b), including the present study (rpoSdeficient $E$. coli was $63 \pm 17 \mathrm{MU}$, wild-type $E$. coli was $42 \pm 5 \mathrm{MU}$ after $8 \mathrm{~h}$ incubation). RpoS has a strong negative effect on the expression of ompF. When $r p o S$-mutant $E$. coli was produced in rich medium, the rate of OmpF synthesis was considerably higher than that of the wild type, and about the same amount of OmpC was produced as in the wild type in nutrient broth medium after $18 \mathrm{~h}$ incubation (Darcan \& Özkanca 2008).

The survival time of Escherichia coli was observed to decrease when porin genes (ompC and ompF) were mutated under photooxidative stress in Black Sea water (Tables $2 \& 3$ ). However the expression of $o m p C$ and ompF of E. coli decreased under photooxidative stress (Figs. 1-4). Therefore, when comparing the synthesis of porin and the culturability results with each other, a conflict between the decrease in porin synthesis and the need for porin proteins for culturability under photooxidative stress in brackish sea water arises, one that is rather difficult to explain. Aquatic environments include various factors (such as $\mathrm{pH}$, osmolarity, and starvation) that affect the survival of bacteria. The reduction in synthesis of porins is not a consequence of oxidative damage under photooxidative stress. Reduction of $o m p C$ and $o m p F$ is likely under transcriptional or translational control. As shown in Fig. 5, porin synthesis is very complex and includes many other factors. In addition, the detailed porin control mechanism under photooxidative stress is unknown.

The present study determined that the expression of ompC and ompF decreased under photooxidative stress in Black Sea water. The expression of porins was not regulated by RpoS and EnvZ under photooxidative stress. For the first time, this study determined that the expression of ompC was positively and indirectly controlled by RpoS in brackish water.

Acknowledgements. I thank H. Kobayashi (Chiba University, Japan), T. Ferenci (Sydney University, Australia) and R. Matthews (Michigan University, USA) for kindly providing the Escherichia coli strains.

\section{LITERATURE CITED}

Achouak W, Heulin T, Pagès JM (2001) Multiple facets of bacterial porins. FEMS Microbiol Lett 199:1-7

> Arana I, Muela A, Orruño M, Seco C, Garaizabal I, Barcina I (2010) Effect of temperature and starvation upon survival strategies of Pseudomonas fluorescens CHA0: comparison with Escherichia coli. FEMS Microbiol Ecol 74: 500-509

> Atlung T, Ingmer H (1997) H-NS: a modulator of environmentally regulated gene expression. Mol Microbiol 24:7-17

Batchelor E, Walthers D, Kenney LJ, Goulian M (2005) The Escherichia coli CpxA-CpxR envelope stress response system regulates expression of the porins OmpF and OmpC. J Bacteriol 187:5723-5731

> Chou JH, Greenberg JT, Demple B (1993) Posttranscriptional repression of Escherichia coli OmpF protein in response to redox stress: positive control of the micF antisense RNA by the soxRS locus. J Bacteriol 175: 1026-1031

- Chubiz LM, Rao CV (2011) Role of the mar-sox-rob regulon in regulating outer membrane porin expression. J Bacteriol 193:2252-2260

$>$ Dahl TA, Midden WR, Hartman PE (1989) Comparison of killing of gram-negative and gram-positive bacteria by pure singlet oxygen. J Bacteriol 171:2188-2194

Darcan C (2005) An investigation on the effect of $\mathrm{pH}$, starvation and osmotic stress on outer membrane porin protein synthesis level of Escherichia coli in the Black Sea water. $\mathrm{PhD}$ thesis, Institute of Science and Technology, Ondokuz Mayıs University

$>$ Darcan C, Aydın E (2012) fur mutation increases the survival time of Escherichia coli under photooxidative stres in aquatic environments. Acta Biol Hung 63:399-409

Darcan C, Özkanca R (2008) OmpC-OmpF porin proteins expressions of Escherichia coli in nutrient broth and the role of EnvZ, OmpR, H-NS, AcP and RpoS on this expression. DPU J Sci 4:1-10 (in Turkish)

> Darcan C, Özkanca R, Flint KP (2003) Survival of nonspecific porin-deficient mutants of Escherichia coli in black sea water. Lett Appl Microbiol 37:380-385

> Darcan C, Özkanca R, İdil Ö, Flint KP (2009a) Viable but non-culturable state (VBNC) of Escherichia coli related to EnvZ under the effect of $\mathrm{pH}$, starvation and osmotic stress in sea water. Pol J Microbiol 58:307-317

Darcan C, Özkanca R, Idil Ö (2009b) The role of RpoS, H-NS and $\mathrm{AcP}$ on the $\mathrm{pH}$-dependent $\mathrm{OmpC}$ and $\mathrm{OmpF}$ porin expressions of Escherichia coli at different $\mathrm{pH}$. Afr J Biotechnol 8:1845-1854

> De la Cruz MÁ, Calva E (2010). The complexities of porin genetic regulation. J Mol Microbiol Biotechnol 18:24-36

$>$ Deighan P, Free A, Dorman CJ (2000) A role for the Escherichia coli H-NS-like protein StpA in OmpF porin expression through modulation of micF RNA stability. Mol Microbiol 38:126-139

Delihas N, Forst S (2001) MicF: an antisense RNA gene involved in response of Escherichia coli to global stress factors. J Mol Biol 313:1-12

> Ferrario M, Ernsting BR, Borst DW, Wiese DE, Blumanthal RM, Matthews RG (1995) The leucine-responsive regulatory protein of Escherichia coli negatively regulates transcription of ompC and micF and regulates translation of ompF. J Bacteriol 177:103-113

> Forst S, Delgado J, Inouye M (1989) Phosphorylation of 
OmpR by the osmosensor EnvZ modulates the expression of the $o m p F$ and ompC genes in Escherichia coli. Proc Natl Acad Sci USA 86:6052-6056

Gauthier MJ, Benson SA, Flatau GN, Clement RL, Breittmayer VA, Munro PM (1992) OmpC and OmpF porins influence viability and culturability of Escherichia coli cells incubated in seawater. Microb Releases 1:47-50

Goosen N, van de Putte P (1995) The regulation of transcription initiation by integration host factor. Mol Microbiol 16:1-7

Greenberg JT (1989) Adaptive response to oxidative stress in Escherichia coli. PhD thesis, Harvard University, Cambridge, MA

Hall MN, Silhavy TJ (1981) The ompB locus and the regulation of the major outer membrane porin proteins of Escherichia coli K12. J Mol Biol 146:23-43

Hobbie JE, Daley RJ, Jasper S (1977) Use of nuclepore filters for counting bacteria by fluorescence microscopy. Appl Environ Microbiol 33:1225-1228

İdil Ö, Özkanca R, Darcan C, Flint KP (2010) Escherichia coli: dominance of red light over other visible light sources in establishing viable but nonculturable state. Photochem Photobiol 86:104-109

İdil Ö, Darcan C, Özkanca R (2011) The Effect of UV-A and Different Wavelengths of Visible Lights on survival of Salmonella typhimurium in seawater microcosms. J Pure Appl Microbiol 5:581-592

Lan CY, Igo MM (1998) Differential expression of the OmpF and OmpC porin proteins in Escherichia coli K-12 depends upon the level of active OmpR. J Bacteriol 180: $171-174$

> Liu X, Ferenci T (2001) An analysis of multifactorial influences on the transcriptional control of ompF and ompC porin expression under nutrient limitation. Microbiology 147:2981-2989

- Matsubara M, Kitaoka SI, Takeda SI, Mizuno T (2000) Tuning of the porin expression under anaerobic growth conditions by His-to-Asp cross-phosphorelay through both the EnvZ-osmosensor and ArcB-anaerosensor in Escherichia coli. Genes Cells 5:555-569

Miller JH (1992) A short course in bacterial genetics. Cold Spring Harbor Laboratory Press, Cold Spring Harbor, NY

Muela A, García-Bringas JM, Seco C, Arana I, Barcina I (2002) Participation of oxygen and role of exogenous and endogenous sensitizers in the photoinactivation of Escherichia coli by photosynthetically active radiation, UV-A and UV-B. Microb Ecol 44:354-364

Muela A, Seco C, Camafeita E, Arana I, Orruño M, López JA, Barcina I (2008) Changes in Escherichia coli outer membrane subproteome under environmental conditions inducing the viable but nonculturable state. FEMS

Editorial responsibility: Christine Paetzold,

Oldendorf/Luhe, Germany
Microbiol Ecol 64:28-36

> Munro PM, Gauthier MJ, Breittmayer VA, Bongiovanni J (1989) Influence of osmoregulation processes on starvation survival of Escherichia coli in seawater. Appl Environ Microbiol 55:2017-2024

Nikaido H (2003) Molecular basis of bacterial outer membrane permeability revisited. Microbiol Mol Biol Rev 67: 593-656

Özkanca R, Flint KP (2002) The effect of starvation stress on the porin protein expression of Escherichia coli in lake water. Lett Appl Microbiol 35:533-537

Özkanca R, Şahin N, Işik K, Kariptaş E, Flint KP (2002) The effect of toluidine blue on the survival, dormancy and outer membrane porin proteins (OmpC and $\mathrm{OmpF}$ ) of Salmonella typhimurium LT2 in seawater. J Appl Microbiol 92:1097-1104

Pagès JM, James CE, Winterhalter M (2008) The porin and the permeating antibiotic: a selective diffusion barrier in Gram-negative bacteria. Nat Rev Microbiol 6: 893-903

Painbeni E, Caroff M, Rouviere-Yaniv J (1997) Alterations of the outer membrane composition in Escherichia coli lacking the histone-like protein HU. Proc Natl Acad Sci USA 94:6712-6717

Pratt LA, Hsing W, Gibson KE, Silhavy TJ (1996) From acids to osmZ: multiple factors in $>$ uence synthesis of the OmpF and OmpC porins in Escherichia coli. Mol Microbiol 20:911-917

Rozen Y, Belkin S (2001) Survival of enteric bacteria in seawater. FEMS Microbiol Rev 25:513-529

Sato M, Machida K, Arikado E, Saito H, Kakegawa T, Kobayashi H (2000) Expression of outer membrane proteins in Escherichia coli growing at acid pH. Appl Environ Microbiol 66:943-947

Sinton L, Hall C, Braithwaite R (2007) Sunlight inactivation of Campylobacter jejuni and Salmonella enterica, compared with Escherichia coli, in seawater and river water. J Water Health 5:357-365

Slauch JM, Garrett S, Jackson DE, Silhavy TJ (1988) EnvZ functions through OmpR to control porin gene expression in Escherichia coli K-12. J Bacteriol 170:439-441

Storz G, Imlay J (1999) Oxidative stress. Curr Opin Microbiol 2:188-194

Thelaus J, Andersson A, Mathisen P, Forslund AL, Noppa L, Forsman M (2009) Influence of nutrient status and grazing pressure on the fate of Francisella tularensis in lake water. FEMS Microbiol Ecol 67:69-80

> Zheng M, Doan B, Schneider TD, Storz G (1999) OxyR and SoxRS regulation of fur. J Bacteriol 181:4639-4643

> Ziegelhoffer EC, Donohue TJ (2009) Bacterial responses to photo-oxidative stress. Nat Rev Microbiol 7:856-863

Submitted: January 18, 2012; Accepted: June 26, 2012

Proofs received from author(s): October 4, 2012 